\title{
Correction to: Numerical Simulation of Turbulent Flow and Heat Transfer in a Three-Dimensional Channel Coupled with Flow Through Porous Structures
}

\author{
Guang Yang ${ }^{1,2}$ (D) Bernhard Weigand ${ }^{2} \cdot$ Alexandros Terzis $^{2} \cdot$ Kilian Weishaupt $^{3} \cdot$ \\ Rainer Helmig 3
}

Published online: 8 May 2018

(c) Springer Science+Business Media B.V., part of Springer Nature 2018

\section{Correction to: Transp Porous Med (2018) 122:145-167 https://doi.org/10.1007/s11242-017-0995-9}

In our recent paper, Yang et al. Transp Porous Med (2018) 122:145. https://doi.org/10.1007/ s11242-017-0995-9, the correct Nusselt numbers in Sections "3.2 Grid Independence Test" and "4.7 Heat Transfer in the Porous Structure" should be the shown values multiplied by 4. This has been a post-processing mistake when producing the figures. This leads to the following corrections:

- Table 1: $N u_{1}=365.4916, N u_{2}=369.3700$ and $N u_{3}=371.2536$.

- The original values in the colormaps of Fig. 16 should be multiplied by 4 .

- The original $Y$ axis values of Fig. 17 should be multiplied by 4 .

- The original $X$ and $Y$ axes values of Fig. 18 should be multiplied by 4 .

- Quantity $n$ in Eq. (12) should be: $n=1.704-0.084 V R-1.536 V R \delta+1.824 \delta V R^{2}$, so the constant has been multiplied by 4 .

Please note that all the results, discussions and conclusions remained valid, and all the variation trends of Nusselt number stated in the cited paper remain the same.

The original article can be found online at https://oi.org/10.1007/s11242-017-0995-9.

Guang Yang

y_g@sjtu.edu.cn; guang.yang@itlr.uni-stuttgart.de

1 Institute of Refrigeration and Cryogenics, Shanghai Jiao Tong University, 200240 Shanghai, China

2 Institut für Thermodynamik der Luft- und Raumfahrt, Universität Stuttgart, 70569 Stuttgart, Germany

3 Institut für Wasser- und Umweltsystemmodellierung, Universität Stuttgart, 70569 Stuttgart, Germany 